\title{
Intergranular Corrosion Behavior of Nickel Base Superalloys 600, 690 And 693
}

\author{
Pradeep Kumar Samantaroy \\ Department of Chemistry \\ Rayagada Autonomous College, Rayagada \\ Odisha, India-765001
}

\begin{abstract}
Three nickel base superalloys namely Alloy 600, Alloy 690 and Alloy 693 are studied to evaluate their intergranular corrosion resistance in $65 \%$ boiling nitric acid medium for five periods with the duration of 48 hour in each period referring Huey test (ASTM 262, practice C). The tests were conducted for the alloys under as-received, solution annealed \& sensitized condition. The weight loss was measured after each period of testing. The tested specimens were observed under SEM. Severe grain boundary attack was observed in Alloy 600 and Alloy 693 with dissolution of matrix. Alloy 690 showed excellent resistance towards intergranular corrosion compared to Alloy 693 and Alloy 600 in as-received as well as both heat treated conditions.
\end{abstract}

Keywords: Alloy 600, Alloy 690, Alloy 693, Intergranular Corrosion, Practice C, Nitric Acid

\section{INTRODUCTION}

Generally, the passive film formed on a material tends to be uniform and free of pores. The properties of the film change in the areas where the material surface is associated with the grain boundary precipitates. Such heterogeneity is dangerous since it weakens the stability of the material without producing much change in the outward appearance. Corrosion attack under such circumstances leads to intergranular attack, which may result in the loss of strength and ductility of the material. Intergranular attack is accelerated by potential differences between grain and grain boundaries, i.e. attack is determined by availability of anodic sites at grain boundaries. Therefore, to create anodic sites, the specimen should get passivated. The usual form of intergranular corrosion (IGC) occurs due to sensitization which is the depletion of chromium and formation of chromium carbide precipitates adjacent to grain boundaries. The degree of sensitization of a material depends upon the concentration of chromium and carbon and generally increases with increase in the concentration of carbon and decreases with chromium concentration. Chromium from the solid solution is utilized for $\mathrm{Cr}$-rich $\mathrm{Cr}_{23} \mathrm{C}_{6}$ formation resulting in lower chromium content adjacent to such carbides along the grain boundaries. Such chromium depleted regions are vulnerable to corrosive attack, because it does not contain sufficient chromium to form passive film.

In strong oxidizing nitric acid medium corrosion of a material occurs in the transpassive zone. If any species which reduces the transpassive potential is present in the solution, then it will affect the corrosion resistance of the material. Similarly, corrosion rate increases, if any species tends to increase the oxidizing power of the medium. However, general corrosion rate is less in the case of materials forming stable passive film on the surface. Presence of inclusions (mainly sulphides of iron and manganese) in the matrix leads to severe pitting and intergranular corrosion. Hence, these issues must be taken into account at the time of manufacturing the any storage tank material. The issue becomes vital when the tank is to be made up for storage of nuclear high level waste containing nitric acid as one of its main constituent. Therefore, the storage material for use with nitric acid medium must have low level of inclusions, should be resistant to sensitization, intergranular corrosion and should have low general corrosion rate $[1,2]$.

The evaluation of the susceptibility to intergranular corrosion is made according to the ASTM A-262 Standard Practice C [3], (a procedure for conducting the boiling nitric acid test) by calculating an average corrosion rate over the five 48 hour time period, which is popularly known as Huey test [4]. The results of the test is only a measure of intergranular corrosion resistance of a material and not necessarily a measure of the performance of the material in other corrosive environments, and not a basis for predicting resistance from other forms of corrosion like general corrosion, pitting and stress corrosion cracking.

In our previous investigations, corrosion behavior of three nickel base superalloys (Alloy 600, Alloy 690 and Alloy 693) were studied for the nuclear high level waste (HLW) storage application in as-received as well as heat treated (solution annealed and sensitized) condition using electrochemical polarization technique in simulated HLW, compared against $3 \mathrm{M} \mathrm{HNO}_{3}$ [5-7]. Also, the materials were studied for their pitting corrosion performance in various chloride concentrations [8] and in all the cases it was found that Alloy 690 shows superior corrosion resistance compared to Alloy 600 and Alloy 693. As IGC plays a major role for the selection of storage tank material, it must be evaluated for the above materials. The purpose of this study is to put forward knowledge about the susceptibility to intergranular corrosion 
TABLE 1

\begin{tabular}{lccccccccccccc}
\hline \multicolumn{110}{c}{ Chemical Composition of Ni Based Superalloys } \\
\hline Element & $\boldsymbol{N i}$ & $\boldsymbol{C r}$ & $\boldsymbol{F e}$ & $\boldsymbol{C}$ & $\boldsymbol{S}$ & $\boldsymbol{M n}$ & $\boldsymbol{C u}$ & $\boldsymbol{S i}$ & $\boldsymbol{T} \boldsymbol{i}$ & $\boldsymbol{N} \boldsymbol{b}$ & $\boldsymbol{N}$ & $\boldsymbol{A l}$ & $\boldsymbol{M o}$ \\
\hline Alloy 600 & 74.2 & 14.7 & 9.6 & 0.03 & 0.008 & 0.53 & 0.30 & 0.15 & 0.26 & - & - & 0.3 & 0.30 \\
\hline Alloy 690 & 60 & 29.6 & 9.05 & 0.017 & 0.0013 & 0.21 & $<0.01$ & 0.25 & 0.2 & 0.02 & $68 \mathrm{ppm}$ & - & - \\
\hline Alloy 693 & 60.9 & 29.3 & 3.96 & 0.097 & 0.002 & 0.19 & $<0.02$ & 0.04 & 0.42 & 1.86 & - & 3.19 & - \\
\hline
\end{tabular}

of the three nickel base super alloys which are candidate materials for the nuclear high level waste storage application.

\section{EXPERIMENTAL}

\section{A. Materials and Heat Treatment}

Three nickel base superalloys Alloy 600, Alloy 690 and Alloy 693 were used for this investigation, for which the compositions are given in Table 1 . The condition of heat treatment to carry out solution annealing and sensitization are mentioned in Table 2. The as-received specimens were solution annealed according to the temperature and time mentioned in Table 2 and immediately quenched in water. Solution annealing was carried out to dissolve the preexisting carbides in the matrix. Few of the solution annealed specimens were further heat treated at the sensitization condition as per Table 2 and allowed to cool in air to induce sensitization.

\section{B. Specimen Preparation}

As-received, solution annealed and sensitized specimens were polished with 600 grit silicon carbide paper. The specimens were cleaned with soap solution and then with acetone before using for IGC evaluation.

\section{Intergranular Corrosion Study}

In the present investigation the intergranular corrosion resistance of the three nickel base superalloys under various conditions (as-received, solution-annealed and sensitized) were tested using Huey test (ASTM 202A, practice C) [3, 4]. A one litre Erlenmeyer flask equipped with a cold finger type condenser was used for the test. The specimen was hanged using a glass hook. The test solution was $65 \%$ nitric acid, prepared by adding distilled water to concentrated nitric acid. After immersing the specimen in the acid taken in the flask, cooling water was passed through the condenser and the acid was heated to boiling on a hot plate throughout the test period. After each test period, the specimen was removed, rinsed with water, and dried, cleaned with acetone and the weight of the specimen was taken with accuracy up to $0.0001 \mathrm{~g}$.

The effect of boiling nitric acid on the material was estimated by determining the loss of weight of the specimen after each test period of 48 hours and for the total of the test periods 240 hours. The corrosion rates are reported as mils per year.

The rate of corrosion is measured using the following equation;

Rate of corrosion $=472 \times(7290 \times \mathrm{W}) /(\mathrm{A} \times \mathrm{d} \times \mathrm{t})$ mils per year where:

$$
\begin{aligned}
& \mathrm{t}=\text { time of exposure in } \mathrm{h}, \\
& \mathrm{A}=\text { total surface area in } \mathrm{cm}^{2}, \\
& \mathrm{~W}=\text { Weight loss in } \mathrm{g} \text { and } \\
& \mathrm{d}=\text { density of the specimen in } \mathrm{g} / \mathrm{cm}^{3} \text {. }
\end{aligned}
$$

The primary purpose of the Huey test is to detect the susceptibility of the alloys to intergranular corrosion due to harmful carbide precipitation. During the test, selective dissolution occurs in the chromium depleted zones and the dissolution of carbides, intermetallics, phosphides and sulphides, if present [9]. During each period of testing use of fresh nitric acid is essential. This is because the concentration of hexavalent chromium ions in $65 \%$ boiling nitric acid keeps on increasing with time, which would accelerate the corrosion attack on the specimen [10]. This attack is most dramatic above the concentration of $30 \mathrm{ppm}$ chromium ions in the solution [11]. It has been demonstrated that change of nitric acid after every $48 \mathrm{~h}$ minimizes the buildup of chromium ions even when severe sensitized specimen is tested. However, the hexavalent chromium ion must be kept to a minimum concentration during the entire exposure period.

\section{Microscopy Analysis}

The post experimented specimens were observed under

\begin{tabular}{|c|c|c|c|}
\hline \multicolumn{4}{|c|}{ Heat Treatment Parameters } \\
\hline \multicolumn{2}{|c|}{ Material } & Temp $\left({ }^{0} \mathrm{C}\right)$ & Time (min) \\
\hline \multirow{2}{*}{ Alloy 600} & SA & 1120 & 60 \\
\hline & SEN & 800 & 60 \\
\hline \multirow{2}{*}{ Alloy 690} & SA & 1150 & 30 \\
\hline & SEN & 700 & 60 \\
\hline \multirow{2}{*}{ Alloy 693} & SA & 1050 & 30 \\
\hline & SEN & 700 & 60 \\
\hline
\end{tabular}
"SNE3000M Korea" make desktop mini-SEM to study the morphology and extent of intergranular attack.

TABLE 2 
TABLE 3

\begin{tabular}{|c|c|c|c|c|c|c|c|c|}
\hline \multicolumn{9}{|c|}{ Corrosion Rates Determined After Huey's Test For Heat-Treated Specimens } \\
\hline \multirow{2}{*}{\multicolumn{2}{|c|}{ Material }} & \multicolumn{7}{|c|}{ Corrosion Rate (mils per year) } \\
\hline & & 24 & 48 & 96 & 144 & 192 & 240 & Average \\
\hline \multirow{3}{*}{ Alloy 600} & AR & 2829 & - & - & - & - & - & 2829 \\
\hline & SA & 4.8 & - & - & - & - & - & 4.8 \\
\hline & SEN & 3540 & - & - & - & - & - & 3540 \\
\hline \multirow{3}{*}{ Alloy 690} & AR & - & 3.2 & 2.6 & 2.5 & 2.8 & 3.1 & 2.8 \\
\hline & SA & - & 2.16 & 2.16 & 2.16 & 2.16 & 2.16 & 2.16 \\
\hline & SEN & - & 3.21 & 3.23 & 3.23 & 3.24 & 3.25 & 3.23 \\
\hline \multirow{3}{*}{ Alloy 693} & AR & - & 258 & 832 & 1034 & 1042 & 960 & 825 \\
\hline & $\mathrm{SA}$ & - & 2.93 & 2.95 & 2.96 & 2.98 & 2.99 & 2.97 \\
\hline & SEN & - & 1255 & 1259 & 1262 & 1260 & 1262 & 1261 \\
\hline
\end{tabular}

\section{RESULTS \& DISCUSSION}

The corrosion rate of the three nickel base superalloys under as-received condition, after each period of testing in $65 \%$ boiling nitric acid is given in Table 3. During the testing of as-received Alloy 600, the material failed completely in the first $48 \mathrm{~h}$, and the weight loss was more than $50 \%$ which implies very poor intergranular corrosion resistance of the alloy. Hence, the testing was restricted to only $24 \mathrm{~h}$ and weight loss was measured to evaluate the corrosion rate. The corrosion rate obtained for this alloy was 2829 mils per year. It could be observed from Table 3 that the corrosion rate of Alloy 693 is very high compared to Alloy 690 under as-received condition. As-received Alloy 690 showed an average corrosion rate of 2.8 mils per year, whereas as-received Alloy 693 showed 825 mils per year. The SEM images of the specimens after Huey test are represented in Fig. 1. Severe intergranular corrosion with grain drop was observed in Alloy 600 and Alloy 693 under as-received condition, whereas the grain boundary attack was very less in as-received Alloy 690 with no grain drop. However, intergranular attack was observed at the twin boundaries of as-received Alloy 690. Severe dissolution with pitting identified in the matrix of as-received Alloy 600, (Fig. 1b) along with higher corrosion rate could be attributed to the lower chromium content as well as higher sulphur content in the matrix. The higher corrosion rate of Alloy 693 under as-received condition is due to the higher percentage of carbon $(0.09 \%)$. Microstructural characterization of as-received Alloy 693 revealed the presence of higher amount of precipitates in the matrix as well as adjacent to grain boundaries, where selective dissolution occurs during the testing and hence, increased the corrosion rate. In addition, the smaller grain size of Alloy 693 could be responsible for higher intergranular corrosion. Smaller grain size implies shorter diffusion path and quicker carbon consumption and hence, higher intergranular corrosion [12].

As mentioned above, the intergranular corrosion testing for Alloy 600 under as-received condition was restricted to $24 \mathrm{~h}$; therefore, the same time period was applied to the heat treated (sensitized and solution annealed) Alloy 600 specimens also. The corrosion rate of all the three heat treated nickel base superalloys after each period of testing in $65 \%$ boiling nitric acid is given in Table 3. The SEM images of the specimens obtained after Huey test are shown in Fig. 2. Intergranular corrosion was observed in all the cases. The solution-annealed Alloys 690 and 693 did not show any significant weight loss after $240 \mathrm{~h}$ testing and the corrosion rate was found to be less than 3 mils per year and hence, exhibited excellent intergranular corrosion resistance compared to the as-received and sensitized specimens. Some grain boundaries in the solution-annealed Alloy 600 specimen were corroded; however, along many boundaries, the corrosion attack was only in localized areas with parts of the boundary remaining unattacked. The corrosion attack on the solution-annealed Alloy 693 was along the grain boundaries. The grain boundaries of solution-annealed Alloy 690 were also marginally attacked. The sensitized Alloy 600 and 693 specimens corroded to an extent that many grains dropped from their surface, but no grain had dropped from the sensitized Alloy 690 specimen. The grain boundaries of the sensitized Alloy 690 were also attacked and the precipitates within the grains had been etched away.

When these austenitic nickel base alloys are extensively heated and allowed to cool slowly in the sensitization temperature range, chromium-rich carbide precipitates along the grain boundaries leading to chromium depletion along the grain boundaries, which causes sensitization. When the sensitized material is exposed to corrosive media, intergranular corrosion (IGC) takes place. It is well known that during heat treatment elements like $\mathrm{Si}, \mathrm{Mn}, \mathrm{S}, \mathrm{P}$ and B segregate to the grain boundaries of the alloy and such segregation results in the formation of weak passive films at the grain boundaries, which rapidly dissolve resulting in selective IGC. When the concentration of acid increases beyond $8 \mathrm{~N}$ or the temperature increases beyond $80{ }^{\circ} \mathrm{C}$, the protective $\mathrm{Cr}_{2} \mathrm{O}_{3}$ passive film formed over the surface gets oxidized to $\mathrm{CrO}_{3}$ with the transformation of $\mathrm{Cr}^{3+}$ ions into soluble $\mathrm{Cr}^{6+}$ ions [13]. 

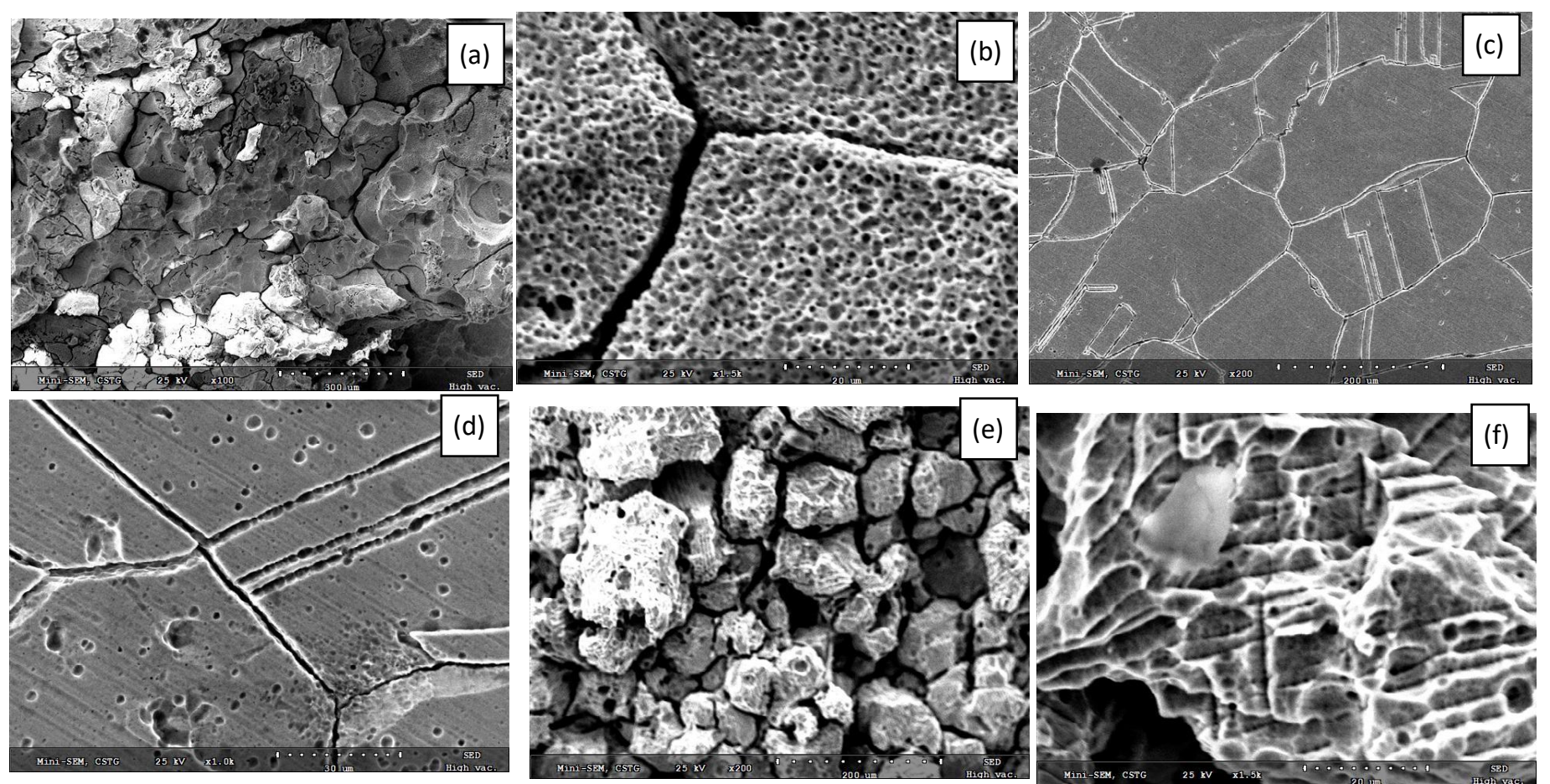

Fig. 1: SEM images obtained after Huey's test: (a) and (b) for Alloy 600, (c) and (d) for Alloy 690, (e) and (f) for Alloy 693

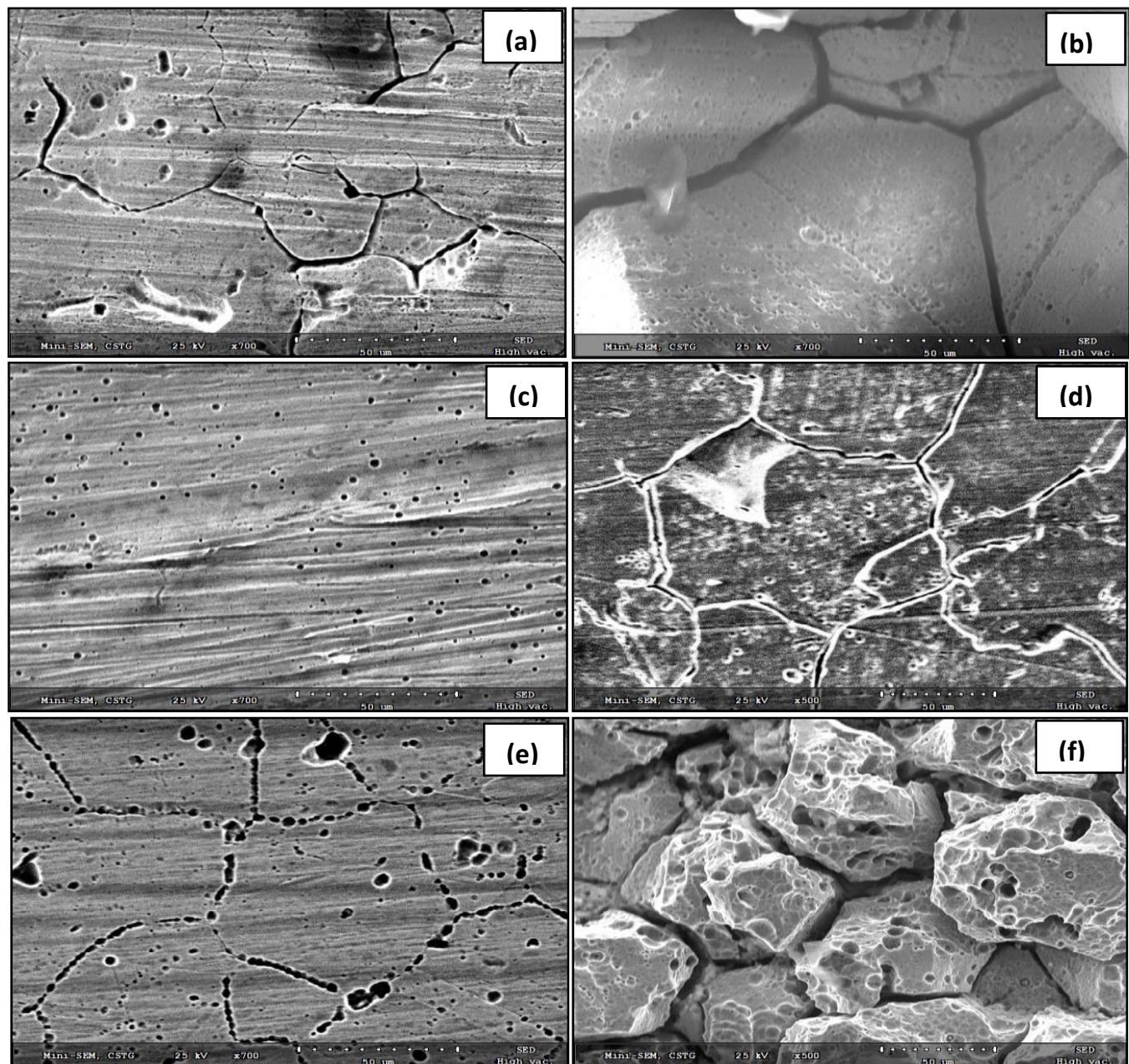

Fig. 2: SEM images obtained after Huey test: (a) SA and (b) SEN Alloy 600; (c) SA and (d) SEN Alloy 690; (e) SA and (f) SEN Alloy 693 


\section{CONCLUSION}

From the above Practice $\mathrm{C}$ experiments, it is concluded that Alloy 690 showed superior intergranular corrosion compared to Alloy 693 followed by Ally 600 in asreceived, sensitized as well as solution annealed condition.

\section{ACKNOWLEDGEMENTS}

The author acknowledges Dr. U. Kamachi Mudali for his valuable support in this work. The author also thanks Corrosion Science \& Technology Group, Indira Gandhi Centre for Atomic Research, Kalpakkam, India for their support in completing the work.

\section{REFERENCES}

[1] U. Kamachi Mudali, R. K. Dayal, J.B. Gnanamurthy, J. Nucl. Mater., vol 203: p.73, 1993.

[2] S. Girija, V.R. Raju, U. Kamachi Mudali, R.K. Dayal, Corros. Eng. Sci. Tech., vol 38:p p 309, 2003
[3] ASTM Standard Practice C 262-93a, "Standard Practice for Detecting Susceptibility to Intergranular Attack in Austenitic Stainless Steels," in Annual Book of Standards, Vol. 3.02 (Philadelphia, PA: ASTM, 1988)

[4] W.R. Huey, Corrosion test for research and inspection of alloys, Trans. Am. Soc. Steel Treating, 18, pp. 1126, 1930

[5] P.K. Samantaroy, S. Girija, R. Paul, U. Kamachi Mudali, B. Raj, J. Nucl. Mater.,vol 418: pp. 27, 2011

[6] P.k. Samantaroy, S. Girija, N.G. Krishna, U. Kamachi Mudali, J. Mater. Eng. Perform., vol 22 pp. 1041, 2012.

[7] P.K. Samantaroy, S. Girija, U. Kamachi Mudali, Corrosion, vol 68, pp. 046001-1-046001-13, 2012..

[8] P.K. Samantaroy, S. Girija, U. Kamachi Mudali, , Int. J. Mater. Sci.,vol 3, pp. 170, 2013.

[9] E. Otero, A. Pardo, E. Saenz, M.V. Utrilla, F. J. Perez, Canadian Met. Quart., vol 36, pp. 65, 1997.

[10] M.H. Brown, Corrosion, vol 30, p p. 1, 1974

[11] W. B. Delong, Testing multiple specimens of stainless steels in a modified boiling nitric test apparatus, ASTM STP No. 93, pp $211,1949$.

[12] G. P. Yu, H.C. Yao, Corrosion, vol 46, pp. 391., 1990.

[13] N. Parvathavarthini, U. Kamachi Mudali, L. Nenova, C. Andreev, B. Raj, Met. Mater. Trans. A,vol 43 pp 2069, 2012. 